opiates, benzodiazepine or illicit substances be given carries.

Initiation risks: David Stevenson, 28, had recently returned to the program when he died of an overdose on Nov. 12, 2002. The inquest found that due to a prescription error, Stevenson received an excessive dose of methadone. The jury recommended "more stringent and precise guidelines during the initiation phase."

Dr. Graeme Cunningham, the former chair of the College's methadone governance committee and director of the Homewood Addiction Centre in Guelph, said updated College guidelines (coming Mar. 31) reflect this concern.

Lucas said it is "not uncommon" for doctors to exceed the recommended initiation dose. Latowsky finds this unacceptable. "I can't think of any circumstances where deviation [from this guideline] would be justified. Certain aspects of the guidelines should be more like standards."
The jury also recommended more education for physicians and reassessment every 3 years, rather than only at the end of their first year.

Cunningham believes physicians also need broader training in addiction. "It's like teaching doctors about diabetes, but only talking about insulin," he said. "Doctors are naive and in some cases enabling. It's a huge problem."

Lack of integration: Judith Jenkins, 42, had been in treatment for 10 months when she died Sept. 21, 2003, of "combined drug toxicity." Jenkins was also seeing a psychiatrist, who was unaware that she was taking methadone and prescribed other drugs, including diazepam.

"The left hand didn't know what the right was doing," says Lucas.

The jury recommended random urine screening throughout treatment.

Many of these recommendations will require increased funding. The budget has re- mained stagnant for 3 years at $\$ 225000$ annually, while the number of clients has nearly doubled, says Hillier. "Funding has to be addressed."

Practitioners are often left to manage "on their own," says Latowsky. "There's no money for case management, rehabilitation, psychiatric care, etc. If more services were available, generally these people would do better."

The jury recommended that funding be based on the number of clients.

The College will study all 36 recommendations pertaining to its management of the program, but Latowsky is worried that neither the College nor the province will act on the recommendations. "As long as there's a perception of a safe program and reasonable recommendations, then everyone's happy though nothing may happen. It's much harder to have recommendations followed through with real action." - Barbara Sibbald, CMAJ

\title{
LEGISLATION
}

\section{Privacy versus public safety: reporting of gunshot wounds}

Alberta politicians want to amend the Health Information Act to force doctors to tell police when they are treating a gunshot victim and to disclose $\infty$ that patient's health status.

iे Currently, doctors are prohibited from providing that information unless the police have $\approx$ a court order, the victim is in grave condition, there is an immediate threat to public or indi$§$ vidual safety, or the patient con-

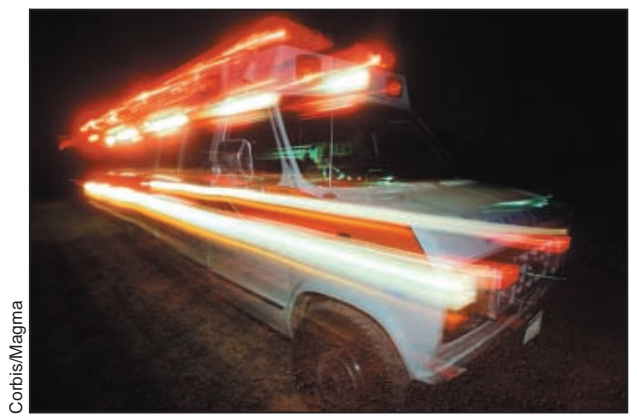

Alberta may require emergency staff to report gunshot wounds. sents. Patient privacy concerns have been at the root of the prohibition until now.

But that protection makes it difficult for investigators to do their jobs, says Tory MLA Thomas Lucaszuk. "Police services are experiencing difficulty obtaining information [about] individuals who go into emergency with wounds indicative of criminal activity, or [from] those they've lost custody of, say, after a car accident," says Lucaszuk, a member of the all-party committee reviewing the legislation.

Critics of the proposed legislative changes say some victims may not seek treatment if police and physicians cooperate in this way.

"That is not a concern I share," says Lucaszuk. "If they have something to hide and choose not to go, that's their choice. My job is to protect lawabiding Albertans."
Although no Canadian jurisdiction currently requires physicians to report gunshot wounds to police, Ontario has introduced legislation that requires public hospitals and health care facilities to report patients with gunshot wounds to the police (CMA7 2004;170:780). The Mandatory Gunshot Reporting Act, which is at the committee stage in the Ontario legislature, is expected to pass this spring, says Adrian Dafoe, a spokesman for Community Safety Minister Monte Kwinter.

"Although individual doctors have expressed certain opinions, medical bodies overall are highly supportive," Dafoe says.

In most provinces, physicians are justified in contacting police only when there is an imminent threat to the victim, to the public, or if the victim is near death. - Lisa Gregoire, Edmonton 